\title{
Work-Softening, High Pressure Phase Formation and Powder Consolidation by HPT
}

\author{
Minoru Umemoto ${ }^{1, a}$, Bui Duc Long ${ }^{1,2, b}$,Yoshikazu Todaka ${ }^{1, c}$ and \\ Koichi Tsuchiya ${ }^{3, d}$ \\ ${ }^{1}$ Dept. of Production Systems Engineering, Toyohashi University of Technology, Toyohashi, Aichi, \\ Japan \\ ${ }^{2}$ School of Materials and Mineral Resources Engineering, Engineering Campus, Universiti Sains \\ Malaysia, 14300 Nibong Tebal, Penang, Malaysia. \\ ${ }^{3}$ Hybrid Materials Center, National Institute for Materials Science,Tsukuba, Ibaraki, Japan \\ aumemoto@martens.pse.tut.ac.jp, bduclong128@gmail.com, ${ }^{\mathrm{a}}$ todaka@martens.pse.tut.ac.jp, \\ dTSUCHIYA.Koichi@nims.go.jp
}

Keywords: HPT, work-softening, consolidation, $\mathrm{Cu}$, high pressure phase, $\mathrm{Ti}$

\begin{abstract}
Among the various severe plastic deformation (SPD) processes, high pressure torsion (HPT) has several unique characteristics. These are applicability of very large strain and deformation under high pressure. Due to these abilities of HPT, several unique phenomena have been observed. In the present paper, three topics were reviewed; 1) work-softening in pure $\mathrm{Cu}, 2$ ) high pressure phase formation in pure $\mathrm{Ti}$ and 3 ) synthesis of $\mathrm{Cu}-\mathrm{NbC}$ composite. Work softening in pure $\mathrm{Cu}$ was observed when low strain rate and high pressure were applied. In Ti high pressure $\omega$ phase is obtained after unloading only when the deformation at high pressure was applied. The volume fraction of $\omega$ phase increased with the increase in the amount of strain. In pure Fe, high pressure $\varepsilon$ phase was not retained at ambient pressure. The bulk $\mathrm{Cu}-\mathrm{NbC}$ composite was synthesized starting from elemental powders. This demonstrates that HPT is an efficient tool for mechanical alloying and cold consolidation.
\end{abstract}

\section{Introduction}

Severe plastic deformation (SPD) has been studied extensively in the last few decades to obtain bulk material with ultrafine grained structures. A number of SPD processes have been proposed, such as equal channel angular pressing (ECAP)[1,2], accumulative roll bonding (ARB)[3], multi directional forging and high pressure torsion (HPT)[1]. All of them are characterized by the applicability of very large plastic strain of more than 4 in equivalent strain at relatively low homologous temperatures. Among these SPD processes, HPT has several unique characteristics, those are, continuous deformation process, large strain and deformation under high pressure. Large strain can be applied by a single process route in HPT while ECAP and ARB are cyclic process and there is an interval between deformation cycles. Thus static recovery takes place in ECAP or ARB during the intervals. Because of large strain, work softening has been observed in pure Al. However, work softening has not been reported in $\mathrm{Cu}$. The large hydrostatic pressure associated with HPT induces phase transformation in certain metals such as pure $\mathrm{Ti}$ [4,5] and pure $\mathrm{Zr}$ [6]. The simultaneous application of large hydrostatic pressure and shear strain results in the formation and stabilization of high pressure phase after unloading. Large strain under high pressure of HPT process is also advantageous to perform mechanical alloying and consolidation of powders. Mechanical alloying makes it possible to produce metal-ceramic composite through in-situ synthesis of fine ceramic particles from supersaturated solid solution.

In the present paper, 1) work-softening in HPTed pure $\mathrm{Cu}, 2$ ) high pressure $\omega$ phase formation in pure $\mathrm{Ti}$ and 3) formation of bulk $\mathrm{Cu}-\mathrm{NbC}$ composite with good electrical conductive and high strength from elemental powders of $\mathrm{Cu}, \mathrm{Nb}$ and graphite, are reported. 


\section{Experimental Procedures}

To investigate work softening, pure $\mathrm{Cu}$ (99.99 of mass \% ) was used. Samples of diameter (Ф) $20 \mathrm{~mm}$ and thickness $(\mathrm{t})$ of $0.85 \mathrm{~mm}$ were deformed by HPT at pressure $(\mathrm{P})$ of $5 \mathrm{GPa}$, with rotation speed of $0.2 \mathrm{rpm}$ up to 10 turns. After deformation, Vickers microhardness was measured along the diameter of the disk samples. Hardness measurements were also done 3.5 months after the HPT deformation to study the age softening at room temperature.

To investigate the high pressure phase formation and its stabilization, commercial pure Ti- $0.03 \% \mathrm{O}$ (Ti- $0.03 \mathrm{Fe}-0.01 \mathrm{~N}-0.01 \mathrm{C}-0.0025 \mathrm{H}), \mathrm{Ti}-0.05 \% \mathrm{O}(\mathrm{Ti}-0.025 \mathrm{Fe}-0.045 \mathrm{O}-0.01 \mathrm{~N}-0.01 \mathrm{C}-0.004 \mathrm{H})$ and Ti-0.12\%O (Ti- $0.087 \mathrm{Fe}-0.116 \mathrm{O}-0.002 \mathrm{~N}-0.004 \mathrm{C}-0.0002 \mathrm{H})$ were used. The samples of $\Phi 10$ and 20 $\mathrm{mm}$ and thickness of $0.85 \mathrm{~mm}$ were deformed by HPT at pressure of $1.5 \mathrm{GPa}$ and 5GPa, with rotation speed of $0.2 \mathrm{rpm}$ up to 10 turns. Specimens were characterized by SEM, TEM $(200 \mathrm{kV}, \Phi 3 \mathrm{~mm}$, $7.5 \mathrm{~mm}$ from centre), XRD (Cu-K $\alpha, \Phi 10 \mathrm{~mm})$, DSC $\left(20 \mathrm{~K} / \mathrm{min}, \mathrm{N}_{2}\right)$, Vickers microhardness tester $\left(4.9 \mathrm{~N}, 10 \mathrm{sec}\right.$ ) and tensile tests (gauge length $1 \mathrm{~mm}$, strain rate $1 \times 10^{-3} \mathrm{~s}^{-1}$ ). The volume fraction of phases was determined from XRD using Rietvelt analysis. The DSC sample with $\Phi 4 \mathrm{~mm}$ was taken from the HPTed sample of $\Phi 20 \mathrm{~mm}$ at position $7.5 \mathrm{~mm}$ from the center.

For powder consolidation experiment, $\mathrm{Cu}(99.9 \%$ purity), $\mathrm{Nb}(99.5 \%)$, and $\mathrm{C}(99.9 \%)$ powders were mixed to have $\mathrm{NbC}$ volume fractions of $0.5,1,2$, and $5 \mathrm{vol} \%$. The mixture of powders of $2.2 \mathrm{~g}$ was processed by HPT at pressure of $5 \mathrm{GPa}$ with rotation speed of $0.5 \mathrm{rpm}$ for 20 turns. As-HPTed samples were annealed in vacuum atmosphere at either $600^{\circ} \mathrm{C}$ or $700^{\circ} \mathrm{C}$ for $1 \mathrm{~h}$. The annealed samples were then characterized using X-ray diffraction (XRD) and, scanning electron microscopy (SEM). Electrical conductivity measurement and tensile test were carried out using samples taken from the $\Phi 20 \mathrm{~mm}$ HPTed sample at position $4.5 \mathrm{~mm}$ from the center. Electrical conducitivity was measured using Ulvac ZEM-1 equipment with sample size of $0.5 \times 2.55 \times 13.6 \mathrm{~mm}$ under air condition. The conductivity was expressed using the IACS (International Annealed Copper Standard, where 100\% IACS is $58.0 \mathrm{~m} / \Omega \mathrm{mm}^{2}$ ) unit. Tensile test was conducted using sample with size of $0.5 \times 1.0 \times 1.7$ $\mathrm{mm}$ at initial strain rate of $10^{-3} \mathrm{~s}^{-1}$.

The shear strain applied by HPT is given by $\gamma=2 \pi r \mathrm{~N} / \mathrm{t}$ ( $r$ : radius; $\mathrm{N}$ : number of HPT revolutions; $\mathrm{t}$ : thickness of the sample) and the von Mises equivalent strain $\varepsilon_{\mathrm{VM}}$ is given by $\varepsilon_{\mathrm{VM}}=\gamma / \sqrt{3}$.

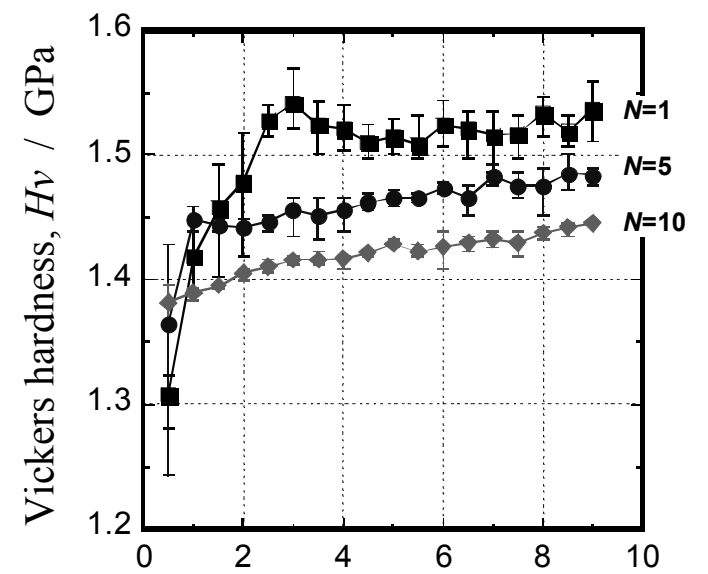

Distance from center, $r / \mathrm{mm}$

Fig. 1 Vickers micro-hardness along a diameter of HPTed sample after 1, 5 and 10 turns.HPT was conducted at $5 \mathrm{GPa}$ with a rotation speed $0.2 \mathrm{rpm}$.

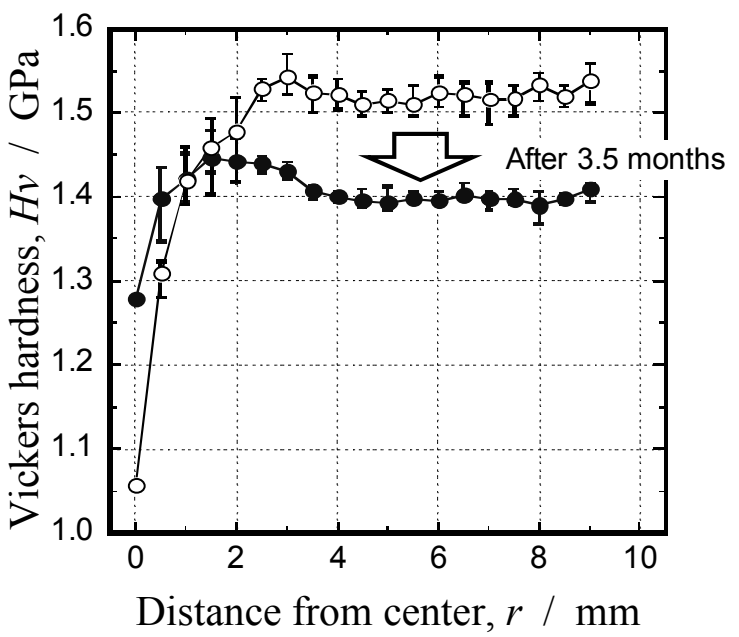

Fig.2 Vickers micro-hardness along a diameter of HPTed sample after 1turns.HPT was conducted at $5 \mathrm{GPa}$ with a rotation speed $0.2 \mathrm{rpm}$.

\section{Results and Discussion}

Work softening in pure Cu. Fig. 1 shows the hardness along the diameter of the pure Cu sample of $\Phi 20 \mathrm{~mm}$ after 1, 5 and 10 turns. After 1 turn, peak hardness is observed along the diameter at around 
$3 \mathrm{~mm}$ from the center with the hardness decreasing with increasing number of turns. Fig. 2 shows the hardness for the sample deformed for 1 turn measured immediately after HPT and also after 3.5 months. It is clear that hardness decreases by room temperature aging and show a clear maximum at around $2 \mathrm{~mm}$ from the center.

Harai et al [7] measured the hardness of pure Al (99.99\%) after HPT. They reported that hardness is a simple function of equivalent strain and saturates at an equivalent strain of 2. Edalati et al [8] also studied pure $\mathrm{Cu}(99.99 \%)$ and reported that the hardness increases with an increase in the equivalent strain at early stages of straining but levels off and enters into a steady-state where the hardness remains constant with further straining. They [8] did not find any work softening like observed in pure Al. The observed difference between the present study and Edalati' work [8] may arise from the difference in the deformation condition since the samples were prepared from same ingot. In the current study a pressure of $5 \mathrm{GPa}$ and speed $0.2 \mathrm{rpm}$ were used while in ref [8] a pressure of $2 \mathrm{GPa}$ and speed of $0.5 \mathrm{rpm}$ were applied. Since the hardness measured in the present study is $1.52 \mathrm{GPa}$ and it is higher than Ref. [8])( 1.3GPa), it is considered that work softening is observed in Ref. [8]) as the deformation rate is faster causing higher temperature rise is high hence softening probably took place during deformation or at least before the hardness measurement.

Recovery in heavily deformed $\mathrm{Cu}$ takes place within hundreds of seconds after the deformation. Kilmametov et al [9] studied microstructure evolution in severely deformed $\mathrm{Cu}$ using high-energy synchrotron light during in situ HPT at room temperature. Their experimental results revealed fast relaxation (on the order of hundreds of seconds) occurred due to annihilation of HPT-induced crystal lattice defects. The early stage relaxation which occurs within hundreds of seconds after HPT will not be able to be detected by hardness measurement. However, softening which takes place up to several months after deformation in pure $\mathrm{Cu}$ is measurable by hardness.

To study work softening, attention should be paid on detailed deformation condition and the duration between deformation and hardness measurement.

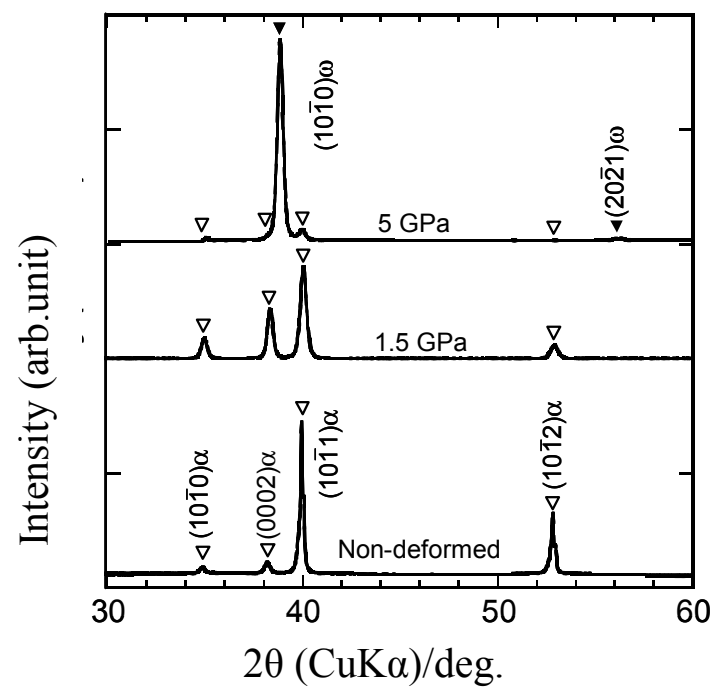

Fig. 3 XRD patterns for Ti- $0.05 \% \mathrm{O}$ before and after HPT deformation $(\Phi 20 \mathrm{~mm}, \mathrm{P}=1.5$ and 5 $\mathrm{GPa}, \mathrm{N}=5$ ).

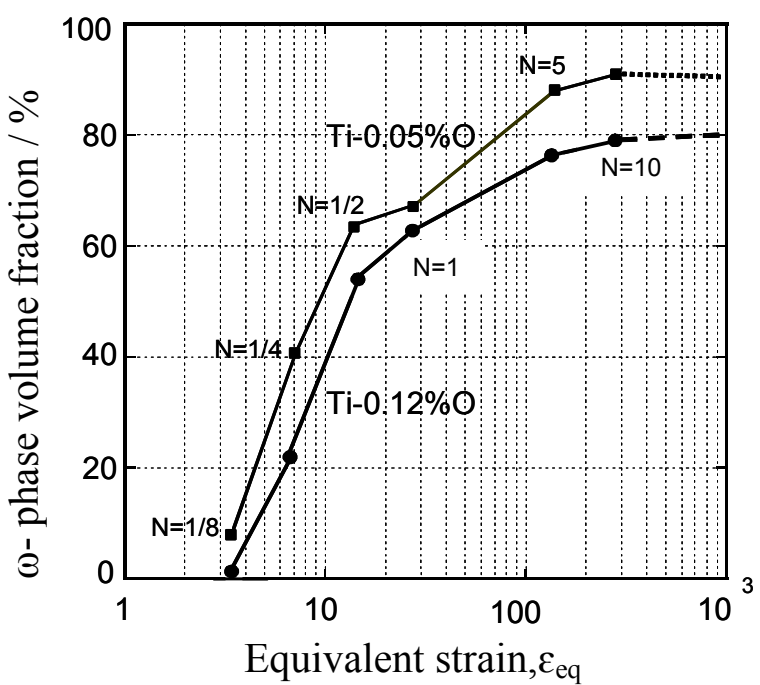

Fig. 4 Effect of oxygen content on the progress of volume fraction of omega phase with strain. $(\Phi 20 \mathrm{~mm} \mathrm{P}=5 \mathrm{GPa})$

High Pressure Phase Formation. The effect of pressure and strain imposed by HPT on phase transformation was studied using pure Ti. The X-ray diffraction (XRD) patterns for the annealed and the HPTed Ti- $0.05 \% \mathrm{O}$ samples $(\mathrm{P}=1.5$ and $5 \mathrm{GPa}, \mathrm{N}=5)$ are shown in Fig. 3. The annealed (non deformed) sample and the sample HPTed at pressure of $1.5 \mathrm{GPa}$ showed peaks corresponding to $\alpha$ 
phase while the sample HPTed at 5 GPa showed peaks corresponding predominantly to $\omega$ phase with small peaks corresponding to $\alpha$ phase. At $5 \mathrm{GPa} \omega$ phase is first detected after $1 / 8$ turns and the volume fraction increases with the number of turns. Figure 4 shows the volume fraction of $\omega$ phase measure by XRD at ambient condition in Ti- $0.05 \% \mathrm{O}$ and Ti- $0.12 \% \mathrm{O}$ after HPT at $5 \mathrm{GPa}$ as a function of equivalent strain. It is seen that the volume fraction of $\omega$ phase gradually increases with the amount of strain. Comparing two curves in Fig. 4 with different oxygen content $(0.05 \%$ and $0.12 \% \mathrm{O}$ ), it is clear that the volume fraction of $\omega$ phase decreases with increase in oxygen content.

Figure 5 shows the XRD patterns for HPTed $(\Phi 10 \mathrm{~mm}, 0.2 \mathrm{rpm}, \mathrm{N}=5)$ high pure $\mathrm{Fe}$ $(\mathrm{Fe}-11 \mathrm{C}-<30 \mathrm{Si}-<30 \mathrm{Mn}-<20 \mathrm{P}-<3 \mathrm{~S}-300 \mathrm{Al}-<20 \mathrm{Ti}-<30 \mathrm{Cr}-<30 \mathrm{Cu}-<2 \mathrm{~B}-8 \mathrm{~N}-14 \mathrm{O}$ in mass ppm). After $\mathrm{HPT}$ at pressure of $15 \mathrm{GPa}$ and $30 \mathrm{GPa}$, peaks corresponding only $\alpha$-Fe is detected. According to the previous studies, $\alpha$-iron undergoes a phase transition to hexagonal close packed (hcp) $\varepsilon$-Fe at room temperature and $13 \mathrm{GPa}$ [10-12].

Similar observations have been reported in HPTed pure Hf [13]. Edalatia et al [13] conducted HPT experiment using $99.99 \%$ purity Hf. They reported that no peak associated with the $\omega$ phase is visible at any deformation conditions including after application of $30 \mathrm{GPa}$. They suggested that, unlike $\mathrm{Ti}$ [4,5] and $\mathrm{Zr}$ [6] reported earlier, straining under high pressure is not effective in Hf to facilitate the phase transformation or to stabilize the $\omega$ phase after unloading.

It is interesting to note that in $\mathrm{Ti}$ or $\mathrm{Zr}$ high pressure $\omega$ phase is stable while in Fe or Hf high pressure phase is not stable at ambient condition. In $\mathrm{Ti}$ or $\mathrm{Zr}$, it is not clear when high pressure $\omega$ phase forms. It forms either after applying pressure or during shear straining under pressure. The dependence of the volume fraction of high pressure $\omega$ phase on the amount of strain can be explained in two ways. One is that the volume fraction of $\omega$ phase depends on the amount of strain and no reversion occurs after unloading. Another is that the specimen is completely transformed to $\omega$ phase after HPT and the reversion of $\omega$ phase on unloading becomes less with increasing the degree of deformation in $\omega$ phase. In Fe and Hf, it is not clear whether a high pressure phase is induced or not, if it is induced by HPT, reversion to original phase occurs on unloading. Further study is needed to clear these points.

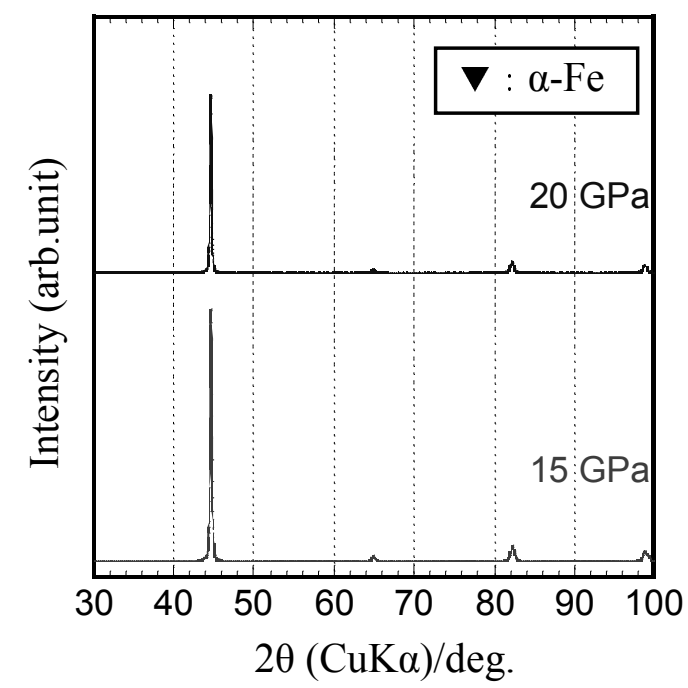

Fig. 5 XRD taken from HPTed sample at 15 and $20 \mathrm{GPa}$.HPT was conducted with a rotation speed $0.2 \mathrm{rpm}$ for 5 turns using specimens of $\mathrm{F} 10 \mathrm{~mm}$.

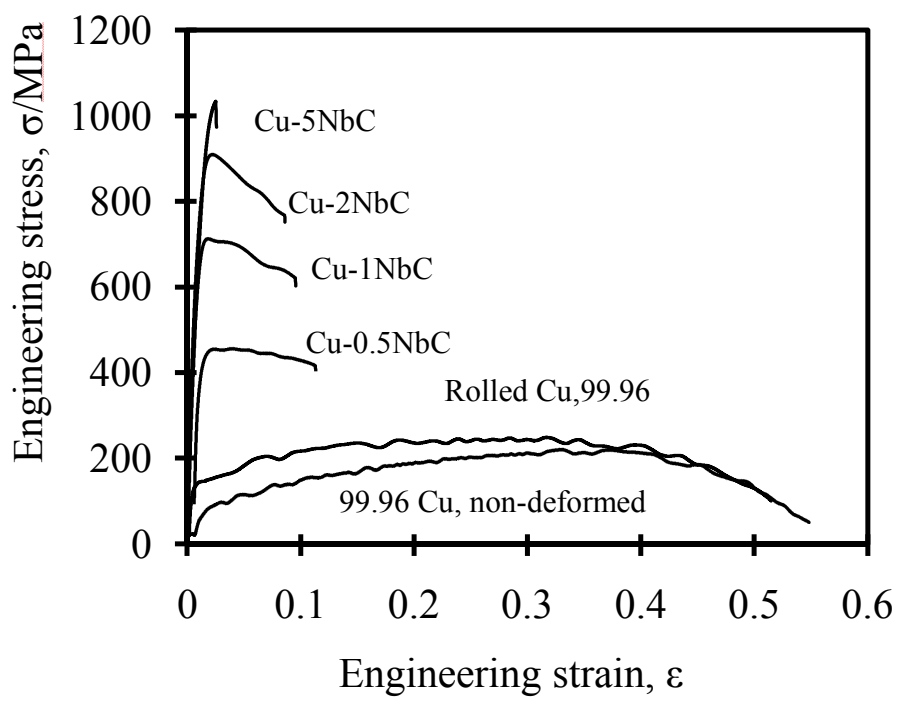

Fig. 6 Tensile stress-strain curves of $\mathrm{Cu}-\mathrm{NbC}$ composites, annealing at $600^{\circ} \mathrm{C}, 1 \mathrm{~h}$.

Mechanical alloying and consolidation. To examine the applicability of HPT process for the consolidation of powders, the mixture of elemental powders of $\mathrm{Cu}, \mathrm{Nb}$ and $\mathrm{C}$ were subjected to HPT to produce $\mathrm{Cu}-\mathrm{NbC}$ composite. During $\mathrm{HPT}$, starting powders of $\mathrm{Nb}$ and $\mathrm{C}$ were severely deformed together with $\mathrm{Cu}$ forming a supersaturated solid solution of $\mathrm{Cu}-\mathrm{Nb}-\mathrm{C}$. After HPT, disk shaped samples are have almost zero porosity $(\rho>99 \%)$ and contain fine $\mathrm{NbC}$ particles (detected by XRD). 
By annealing at 600 and $700^{\circ} \mathrm{C}$ for $1 \mathrm{~h}, \mathrm{XRD}$ peaks of $\mathrm{NbC}$ become large and sharp. Tensile tests were conducted on $\mathrm{Cu}-\mathrm{NbC}$ composites at room temperature after annealing. The engineering stress -strain curves of samples annealed at $600^{\circ} \mathrm{C}$ are shown in Fig.6. It is seen that the tensile strength increases and elongation decreases with the increase in $\mathrm{NbC}$ volume fraction. The tensile strength higher than $600 \mathrm{MPa}$ was obtained when $\mathrm{NbC}$ volume fraction is larger than $1 \%$.

Figure 7 shows the measured tensile strength of $\mathrm{Cu}-\mathrm{NbC}$ composite as a function of electrical conductivity. The data of $0.5,1,2,5 \mathrm{vol} \% \mathrm{NbC}$ samples annealed at 600 and $700^{\circ} \mathrm{C}$ are plotted. It is seen that the electrical conductivity decreases with the increase in tensile strength and $\mathrm{NbC}$ volume fraction. The data of two annealing temperatures lie on a single straight line. When compared with the same $\mathrm{NbC}$ volume fraction, the tensile strength is lower and conductivity is higher for samples annealed at higher temperature.

From the present experiment it becomes clear that the requirements for the materials of electrodes for spot welding, and contact supports (electrical conductivity larger than 50\%IACS and tensile strength higher $600 \mathrm{MPa}$ ) are fulfilled by annealing at $600^{\circ} \mathrm{C}$ and $700^{\circ} \mathrm{C}$ for $1 \% \mathrm{NbC}$, and annealing at $700^{\circ} \mathrm{C}$ for $2 \% \mathrm{NbC}$ samples.

The present work demonstrated that HPT is an effective tool for the consolidation of powders into bulk samples. Starting from elemental powders $\mathrm{Cu}-\mathrm{NbC}$ composite can be synthesized through mechanical alloying and cold-consolidation by HPT.

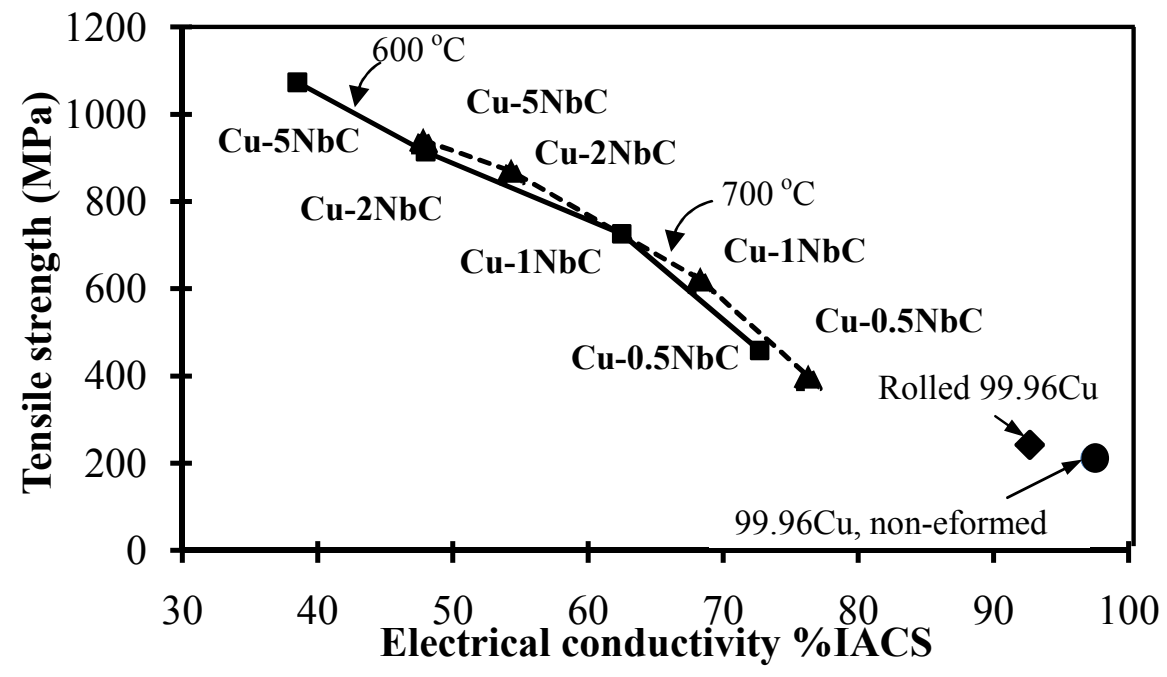

Fig.7 Electrical conductivity of $\mathrm{Cu}-\mathrm{NbC}$ composites vs. tensile strength after HPT (5GPa, 0.5rpm ,20 turns) and annealed at $600{ }^{\circ} \mathrm{C}$ and $700{ }^{\circ} \mathrm{C} 1 \mathrm{~h}$.

\section{Summary}

Unique characteristics of HPT process are reviewed; those are, continuous deformation process, applicability of large strain and deformation under high pressure. The introduced contents are summarized as follows;

1. Work softening is observed in pure $\mathrm{Cu}$ by HPT. The hardness decreases with the increase in the number of HPT turns similar to that observed in pure Al. Work softening is observed only when low strain rate and high pressure are applied. The softening of HPTed pure $\mathrm{Cu}$ sample during long time room temperature aging indicates the importance of the interval between deformation and hardness measurement.

2. High pressure phase can be stabilized to ambient condition by HPT deformation in Ti and $\mathrm{Zr}$ but not in Fe or Hf. The stabilizing mechanism by deformation of high pressure phase is to be studied. 
3. The bulk $\mathrm{Cu}-\mathrm{NbC}$ composite was synthesized from elemental powders by HPT. Good combination of electrical conductivity and tensile strength were obtained. This showed that HPT is a powerful tool not only to consolidate powders but also to produce composite with fine precipitates through the formation of supersaturated solid solution by mechanical alloying.

\section{References}

[1] R.Z. Valiev, R.K. Islamgaliev and I.V. Alexandrov: Prog. Mater. Sci. Vol.45 (2000), p. 103.

[2] V.M. Segal, V.I. Reznikov, A.E. Drobyshevskiyand V.I. Kopylov: Russ. Metall. Vol. 1 (1981), p. 99.

[3] Y. Saito, N. Tsuji, H. Utsunomiya, T. Sakai and R.G. Hong: Scripta Mater. Vol.39 (1998), p.1221.

[4] A.R. Kilmametov, A.V. Khristoforov, G. Wilde and R.Z. Valiev: Z. Kristallogr Suppl. Vol. 26 (2007), p.339.

[5] Y. Todaka, J. Sasaki, T. Moto and M. Umemoto: Scr. Mater.Vol.59 (2008), p. 615.

[6] M.T. Perez-Prado, A.A. Gimazov, O.A. Ruano, M.E. Kassner and A.P. Zhilyaev: Scr. Mater.Vol.58 (2008), p.219.

[7] Y. Harai, Y. Ito and Z. Horita: Scr. Mater. Vol.58 (2008), p.469.

[8] K. Edalati, T. Fujioka and Z. Horita: Mater. Sci. and Eng. A Vol.497 (2008), p.168.

[9] A.R. Kilmametov, G. Vaughan, A.R. Yavari, A. LeMoulec, W.J. Botta and R.Z. Valiev: Mater. Sci. and Eng. A Vol. 503 (2009), p.10.

[10] D. Bancroft, E.L. Peterson and S. Minshall: J. Appl. Phys. Vol.17 (1956), p. 291.

[11] J.C. Jamieson and A.W. Lawson: J. Appl. Phys. Vol.33 (1962), p. 776.

[12] T. Takahashi and W.A. Bassett: Science Vol.145 (1964), p. 483.

[13] K. Edalati, Z. Horita and Y. Mine: Mater. Sci. and Eng. A Vol.527 (2010), p. 2136. 